\title{
Default Risk, Asset Pricing and Debt Control
}

\author{
Lars Grüne*and Willi Semmler ${ }^{\dagger}$
}

February, 2004, revised September 2004

\begin{abstract}
The pricing and control of firms' debt has become a major issue since Merton's (1974) seminal paper. Yet, Merton as well as other recent theories presume that the asset value of the firm is independent of the debt of the firm. However, when using debt finance firms may have to pay a premium for an idiosyncratic default risk and may face debt constraints. We demonstrate that firm specific debt constraints and endogenous risk premia, based on collateralized borrowing, affect the asset value of the firm and, in turn, the collateral value of the firm. In order to explore the interdependence of debt finance and asset pricing of firms we endogenize default premia and borrowing constraints in a production based asset pricing model. In this context then the dynamic decision problem of maximizing the present value of the firm faces an additional constraint giving rise to the debt dependent firm value. We solve for the asset value of the firm with debt finance by the use of numerical dynamic programming. This allows us to solve the debt control problem and to compute sustainable debt as well as firm's debt value.

We want to thank John Donaldson, Martin Lettau, Buz Brock and Harald Uhlig for helpful suggestions and discussions. We also want to thank participants in a workshop at the University of Technology, Vienna, the Macroeconomic Workshop at Columbia University, and the SCE conferences at Yale University, June 2001 and Aix-en-Provence, July 2002, and participants of the workshop on Economic Dynamics in Leiden, June 2002 and the CFS workshop on New Directions in Financial Risk Management, November 2003. We are grateful for comments from two referees of the journal.
\end{abstract}

*Mathematical Institute, University of Bayreuth, Germany, e-mail:Lars.Gruene@unibayreuth.de

${ }^{\dagger}$ Center for Empirical Macroeconomics, Bielefeld and New School University, New York, e-mail:semmlerw@newschool.edu 


\section{Introduction}

Most economic agents (households, firms, banks, governments and countries) extensively borrow to finance economic activity. An important part of risk management is the evaluation and control of credit risk. In this paper we solely focus on evaluating credit risk of firms in the context of a production oriented asset pricing model. Evaluating credit risk of firms amounts to evaluating creditworthiness by solving a debt control problem in the context of a dynamic decision problem. The solution of the dynamic decision problem - in our context of a firm - gives us the firm's asset value. The usual approach is to derive security prices, such as the prices for stocks and bonds from the firm's asset value. In the finance literature it is well recognized that the value of stocks may not be independent of the valuation of the firm's debt. ${ }^{1}$ This paper goes a step further and claims that also the asset value of the firm is not independent of default risk of the firm arising from a firm's borrowing constraint which will, in our context, be defined by creditworthiness of the firm. Our results of default risk dependent asset price value of the firm has implications for at least three strands of literature on firm value.

The first strand of literature goes back to Modigliani and Miller (1958), Black and Scholes (1973) and Merton (1974) where it is presumed that the asset value of the firm is exogenously given by a Brownian motion when the firm's debt is priced. This is usually done by using the adding up theorem, namely $V=S+B$ where $V$ is the asset value, $S$ the value of stocks and $B$ the value of bonds. Furthermore, when short-term interest rates are given and two different firms are presumed to undertake the same investment one can derive the risk structure of interest rates. ${ }^{2}$

The second important strand of literature builds on Tobin's q theory. Here the asset value of the firm is related to a pay-off of the firm and a discount factor. For a firm the present value of its activity is the discounted pay-off with the discount factor determined by the ex-ante rate of return on capital. In Tobin's q theory it is the marginal cash flow, the marginal profit, arising from an increase in a unit of investment, that is priced through a discount rate. The present value of the future marginal cash flow gives us Tobin's q. ${ }^{3}$

A third strand of literature arises from the application of intertemporal general equilibrium models (known as Real Business Cycle Models) to asset

pricing. ${ }^{4}$ Here then too, the asset value of a firm represents an unlevered claim to the stock of capital and thus default risk and claims arising from 
bonds do not impact the asset value of the firm.

We will show that the key to the impact of debt finance on the firm's asset value is the impact of debt finance on credit cost and the sequence of the firm's investment decisions. Firm behavior under finance constraints has been studied starting with Gaskins (1971) and Judd and Petersen (1986) and then recently in Gertler and Gilchrist (1994) and further literature cited below. In this paper we study how finance constraints impact investment and firm value. We presume that, although all firms pursue dynamic investment decisions, they may be valued differently since they face different credit conditions in capital markets and thus may exhibit a different sequence of investments.

The above mentioned literature on asset pricing of firms has not sufficiently considered the implication of the impact of finance premia and borrowing constraints on the value of firms' assets. Usually it is assumed that a firm can undertake investment by borrowing from the capital market at an ex-ante capital cost up to the point where the discounted pay-off is equal to the present value of the firm. Taking this as a benchmark case, we consider the pricing of firms' assets in the case when firms face borrowing constraints or when firms face an external finance premium due to collateralized borrowing. The external finance premium is, in this literature, often interpreted as default premium reflecting firm specific default risk. It is the firm specific default risk that will give rise to a risk-caused endogenous credit cost and thus an endogenously determined risk structure of interest rates in the sense of Merton (1974).

We also want to study what impact this has on the firm's creditworthiness, the dynamics of its capital stock and its asset value. In pursuing this study, default risk and default premia, in contrast to many other recent theories, will be endogenized and thus will be made state dependent. Allowing to do so may give rise to the fact that for firms with slightly different characteristics different domains of attraction of the capital stock and asset value exist.

An important issue in computing the asset value of the firm is the optimization problem of the firm. ${ }^{5}$ The consumption based asset pricing theory would argue that the objective of the firm is to deliver a stream of dividends for the equity holder. The optimization problem of the firm would then be to maximize the present value of dividends to the share holders, whereby the growth rate of marginal utilities serves as a discount factor ${ }^{6}$ to price the dividend stream.

Yet, we would like to argue that in an environment with debt financed investment of the firm one should be interested in the asset value of the firm and not solely in the equity value of the firm relevant for the share holders. The work on pricing of corporate liability has taken this line of research 
since Merton (1974) and numerous empirical approaches have been pursued to infer from time series data on equity value the asset value of the firm. ${ }^{7}$

We also want to note that if we take the maximization of the equity value for the share holders as optimization problem it is then obvious - since endogenous credit cost reduce net income of the firm before dividends are paid - that the equity value of the firm will be affected by state dependent default premia.

What is, however, important in our formulation of the optimization problem, is that the asset value of the firm will be affected by the sequence of optimal investment decisions of a firm facing idiosyncratic default premia. Thus, in our case, it is this constraint on investment decisions that affects firm value. We are dealing with a complicated constrained optimization problem for the solution of which we need advanced numerical methods.

Another important issue is of how to treat consumption in a production oriented asset pricing model. This issue has been taken up in Grüne, Semmler and Sieveking (2003) where we show that a separation theorem can be applied according to which the computation of the asset value of the firm can be separated from consumption, i.e. the sequence of consumption by which the asset value is eventually consumed. In that paper it is shown that any sequence of consumption decisions, based on some preferences of the consumer, is consistent with our model of asset pricing as long as the asset value remains a constraint to the consumption sequence.

As to our solution method we want to note that those rather complex models cannot be solved analytically. We will make use of a dynamic programming algorithm with adaptively refined grids and a set oriented algorithm to solve the different model variants. Those methods are well suited to study problems when firms face imperfect capital markets and when the risk premia need to be endogenized. ${ }^{8}$

The remainder of the paper is organized as follows. Section 2 discusses the relevant literature. Section 3 introduces the basic dynamic asset pricing model. Section 4 discusses the numerical solution methods. Sections 5 reports the detailed results from our numerical study on the different variants of the model. Section 6 concludes the paper. The appendix provides some technical derivation on the numerical methods that are used to study different variants of the dynamic model. 


\section{Default Risk, Investment and Asset Pric- ing}

As above noted the Modigliani-Miller (1958) and Merton (1974) results follow from the proposition that the capital structure does not affect the firm's asset value. Although, as shown in recent papers, applying Black-Scholes and option pricing, the stock price of the firm can be impacted by the capital structure, yet the asset value, which is split up into stocks and bonds, is independent of the capital structure. ${ }^{9}$ Those results are, however, obtained by assuming an exogenous stochastic process, a Brownian motion, for the asset value, which does not originate, as we will argue later, in a solution of a dynamic decision problem of a firm acting under constraints.

In the tradition of the evaluation of firm's debt using option pricing since Merton (1974), the security price of bonds depends on the value of an underlying asset, the (not observable) asset value of the firm. Defining the value of the firm's asset value by $V$ and debt by $B$, we have $B=F(V, t)$. On the maturity date $t$, one needs to have $V-B>0$ otherwise the firm will default. Thus, the value of debt is

$$
F(V, 0)=\min (V, B)
$$

In terms of a Brownian motion one can write a change of the value of debt as

$$
d B=\left(\alpha_{B} B-C_{B}\right) d t+\delta_{B} B_{t} d z
$$

with $\alpha_{B}, \delta_{B}$ and $C_{B}$ constants. Since $B=F(V, t)$, and given a Brownian motion for the value of the underlying asset, $\mathrm{V}$, a solution of the stochastic equation for the debt, $\mathrm{B}$, depending on the stochastic process for $\mathrm{V}$, can be obtained by using Ito's lemma (see Merton, 1974). Below in the context of a dynamic model, it will be shown that if there are no risk premia and the firm issues debt at a risk free interest rate the debt value of the firm is equal to its creditworthiness and the latter is equal to the firm's asset value. Thus we have as maximum debt capacity $B^{*}=V$. This will, however be different for endogenous risk premium where the risk premia may depend on the extent to which the firm is levered. Then, as shown below, we will have $B^{*}=F\left(V\left(B^{*}\right)\right)$ which is a more difficult problem to solve.

In the second strand of literature, in the literature on Tobin's q, investment is an increasing function of the ratio of the market value of the firm to the replacement cost of the firm's capital. ${ }^{10}$ More properly, it can be shown that the optimal investment is the rate that equates the marginal value of 
installed capital with its marginal adjustment cost. ${ }^{11}$ Here too, a stochastic version may allow for a random variable that could represent randomness of technology, in input and output prices or in demand facing the firm. Given a stochastic process and a capital stock state equation firms are presumed to maximize an expected profit flow, $\pi(k, j)$, less adjustment cost of capital, $\phi(k, j)$, subject to a random process and a capital accumulation equation. A version of this type can be found in Abel and Eberly (1994), which can be written, by disregarding the randomness, as the following Hamilton-JacobiBellman (HJB) equation. Using the notation $f(k, j)=\pi(k, j)-\phi(k, j)$ we can write

$$
\theta V=\max _{j}\{f(k, j)+q(j-\sigma k)\}
$$

where $\theta$ is the discount rate, $k$, capital stock, $j$, investment and $\sigma$, capital depreciation. Tobin's q in the above HJB-equation represents the derivative of the value function, with respect to $k$. For later use we may write $q=$ $V^{\prime}(k)$. Abel and Eberly (1994) show that only under the assumption that the adjustment cost of capital $\phi(k, j)$, is linear homogeneous in $j$ and $k$ Tobin's q equals the average value of capital. From $V(k)=q k$ then one obtains $\frac{V(k)}{k}=q$. Here then too default risk and default premia does not affect firm's asset value and thus asset value represents an unlevered claim to the capital stock. ${ }^{12}$

The same presumption of firm value representing an unlevered claim to the capital stock is also made in recent attempts to employ intertemporal equilibrium models (RBC models) to spell out asset price implications. Numerous variants of the intertemporal equilibrium models have attempted to match asset price predictions with the financial statistics obtained from financial time series data, yet most of them presume that the equity of the firm is not affected by debt finance. Rouwenhorst summarizes the tradition in asset pricing theory by writing that an "...unrealistic aspect of the equity definition is that it represents an unlevered claim to the stock of capital, whereas many firms rely in part on debt to finance productive investments. Because the economy is one in which the Modigliani and Miller propositions hold, there is, strictly speaking, no role for debt financing. By the same token, however, because capital structure does not alter the equilibrium allocations, we can simply assume a particular financial structure and use the complete markets framework to study two sets of contingent claims, corporate debt, and levered equity, that add up in value to the capital stock" (Rouwenhorst, 1995:304). Here again, as stated in this citation, the adding up theorem is supposed to hold.

On the other hand, as above noted, recently there has been much work 
on imperfect capital markets and firm's investment. Many dynamic models have been proposed where the firm operates in an environment of imperfect capital markets. Here the firm may face an idiosyncratic default risk and default premium as well as borrowing constraints. ${ }^{13}$

There are two ways to formalize the impact of credit market conditions on firm value and investment. First, very often borrowing ceilings are assumed which are supposed to prevent agents from borrowing an unlimited amount. There could be various provisions and restrictions for firms' debt issuance. One important way to restrict borrowing is to require that agent's assets serve as collateral. A convenient way to define the debt ceiling is then to assume that the debt ceiling is a fraction of the agents' wealth. Second, it is frequently posited that borrowers face a risk dependent interest rate which is assumed to be composed by a market interest rate (for example, risk-free interest rate) and an idiosyncratic component determined by the individual risk of premium for the borrower. Recently the theory of asymmetric information and costly state verification has been employed, (see Bernanke et al. (1999), for example), where a risk premium is made endogenous by making the default risk dependent on net worth of the borrower, as collateral for borrowing. This gives rise to risk premia that firms have to pay contingent on their net worth. In this paper the impact of both the credit constraint as well as endogenous risk premia on firm's value will be explored.

As to the more specifics of our different model variants we draw on the literature on asymmetric information and costly state verification ${ }^{14}$ in which lenders must pay a cost in order to observe the borrower's realized returns. ${ }^{15}$ This motivates the use of collaterals in credit market models. Uncollateralized borrowing is assumed to pay a larger premium than collateralized borrowing or self-financing. The premium arises from the threat of bankruptcy namely by the cost constituted by auditing, accounting, legal cost, as well as loss of assets arising from asset liquidation.

In terms of observable variables the premium the firm has to pay is interpreted as default premium arising from default risk. ${ }^{16}$ Such a premium drives a wedge between the expected return of the borrower and the risk-free interest rate whereby the premium is positively related to the default cost and inversely related to the borrowers net worth. Net worth is defined as the firm's collateral value of the (illiquid) capital stock less the agent's outstanding obligations. Following Bernanke, Gertler and Gilchrist (1999) we measure the inverse relationship between the risk premium (default premium) and net worth in a function such as 


$$
H(k(t), B(t))=\frac{\alpha_{1}}{\left(\alpha_{2}+\frac{N(t)}{k(t)}\right)^{\mu}} \theta B(t)
$$

with $H(k(t), B(t))$ the credit cost depending on net worth, $N(t)=k(t)-$ $B(t)$, with $k((t)$ as capital stock and $B(t)$ as debt. The parameters are $\alpha_{1}, \alpha_{2}, \mu>0$ and $\theta$ is the risk-free interest rate. In the analytical and numerical study of the model below we presume that the risk premium will be zero for $N(t)=k(t)$ and thus, in the limit, for $B(t)=0$, the borrowing rate is the risk-free rate. Borrowing at a risk-free rate will be considered here as a benchmark case. ${ }^{17}$

Figure 1 depicts the equ. (1) with the external finance premium which arises if $N(t)<k(t)$, yet note that different firms could face a different slope of such a default premium cost function, see sect. $4.2 .{ }^{18}$

Figure 1 about here

\section{Endogenous Credit Cost}

Note also that even if the default premium is endogenized in the way we have indicated in figure 1 we might want to define constraints for the firm which, in our model, will be given by an upper bound of a debt-capital stock ratio. As we will show both the default risk creating an endogenous credit cost as well as upper borrowing constraints can affect the value of the firm so that the net worth will also become endogenous. Such a case is studied below through the use of a modified HJB-equation and our new numerical methods. Moreover, we want to note that the risk-free rate does not need to be a constant, it could be stochastic and vary over time. ${ }^{19}$

\section{The Model with Endogenized Default Pre- mium and Borrowing Constraints}

Next we specify the dynamic decision problem of a firm that faces such default premia and/or borrowing constraints. We want to note that although our model can be nested in utility theory, we use a separation theorem that permits us to separate the present value problem from the consumption problem. In our model, as in Cochrane $(1991,1996)$, in his production based asset pricing model, asset pricing can be studied without reference to utility theory and a discount factor obtained from the growth rate of marginal utilities. In Grüne, Semmler and Sieveking (2003) an analytical treatment is given of 
why and under what conditions the subsequent dynamic decision problem of a firm can be separated from the consumption problem.

We focus on the firm's intertemporal optimal investment where debt can be continuously issued and retired. In each period the firm does not have to pay attention to the maturity structure of its debt and it does not face one period borrowing constraints. Yet, there can be intertemporal debt constraints that affect the present value of the activity of the firm.

Employing the above theory on default risk and risk premia as formulated in equ. (1), we study the following dynamic decision problem of a firm ${ }^{20}$

$$
\begin{gathered}
V(k)=\operatorname{Max}_{j} \int_{0}^{\infty} e^{-\theta t} f(k(t), j(t)) d t \\
\dot{k}(t)=j(t)-\sigma k(t), \quad k(0)=k . \\
\dot{B}(t)=H(k(t), B(t))-f(k(t), j(t)), B(0)=B_{0}
\end{gathered}
$$

The firm's net income

$$
f(k, j)=a k^{\alpha}-j-j^{\beta} k^{-\gamma}
$$

is generated from capital stock, through a production function, $A k^{\alpha}$, and investment, $j$, is undertaken so as to maximize the present value of net income of (5) given the adjustment cost of capital $\varphi(k, j)=j^{\beta} k^{-\gamma}$. Note that $\sigma>$ $0, \alpha>0, \beta>1, \gamma>0$, are constants. Equ. (3) represents the equation for capital accumulation and equ. (4) the evolution of debt of the firm. Since net income in (5) can be negative the temporary budget constraint requires further borrowing from credit markets and if there is positive net income debt can be retired. ${ }^{21}$

As above shown, we assume that the risk premium in our credit cost function $H(k, B)$ may be state dependent, depending on the capital stock, $k$, and the level of debt $B$ with $H_{k}<0$ and $H_{B}>0$. Note, however, that if we assume that the default risk depends inversely on net worth, as in equ. (1), we get a special case of our model when only the risk-free interest rate determines the credit cost. We then have a linear model with constant credit cost, $\theta$, and a state equation for the evolution of debt such as

$$
\dot{B}(t)=\theta B(t)-f(k, B), \quad B(0)=B_{0}
$$

In this case, which we consider our benchmark case, we would only have to consider the transversality condition $\lim _{t \rightarrow \infty} e^{-\theta t} B(t)=0$, as the non-explosiveness 
condition for debt, to close the model and (2)-(3) would give us the firm's asset value.

In our more general model (2)-(4) representing a decision problem of a firm facing a risk premium we define the limit of $B(t)$ equal to $V(k(t))$ which now represents the creditworthiness, the present value borrowing constraint. The problem to be solved in this paper is how to compute $V(k)$.

If the interest rate $\theta=\frac{H(k, B)}{B}$ is constant ${ }^{22}$, and we have the benchmark case, then as is easy to see, $V(k)$ is in fact the present value of $k$

$$
\begin{gathered}
V(k)=\operatorname{Max}_{j} \int_{0}^{\infty} e^{-\theta t} f(k(t), j(t)) d t \\
\dot{k}(t)=j(t)-\sigma k(t), \quad k(0)=k . \\
\dot{B}(t)=\theta B-f(k(t), j(t)-c(t)), B(0)=B_{0}
\end{gathered}
$$

with $k(0)$ and $B(0)$ the initial value of $k$ and $B$. For any value of debt, $B$, below $B^{*}=V$, holds that $V-B>0$ and the residual remains as equity of the firm.

The more general case is, however, when there is an endogenous default premium. If we have $H(k, B)$, as in equ. (1) and thus equs. (2)-(4) then, the creditworthiness itself becomes difficult to treat. Pontryagin's maximum principle is not suitable to solve the problem with endogenous default premium and endogenous net worth and we thus need to use special numerical methods to solve for the present value and investment strategy of a levered firm.

We can study the difference of models (2)-(4) and (7)-(9) by using the Hamilton-Jacobi-Bellman (HJB) equation. The HJB equation for equs. (7)(9), leaving aside the time subscripts, corresponds to the above mentioned case of the $B^{*}=V$ in sect. 2 and the above first strand of literature. Here we have

$$
\theta V=\max _{j}\left[f(k, j)+\frac{d V(k)}{d k}(j-\sigma k)\right]
$$

In the appendix 1 the HJB-equation (10) is solved for steady state values and below we use dynamic programming which allows us to study the value of the firm and local and global dynamics of its capital stock. Note that $\frac{d V(k)}{d k}$ represents Tobin's q, as in the second strand of literature see appendix 1 and Abel and Eberly (1994). ${ }^{23}$ 
In the general case of equ. (2)-(4) with firm specific default risk and external finance premium as stated in equ. (1) and shown in Figure 1, we have the following modified HJB-equation instead.

$$
H\left(k, B^{*}(k)\right)=\max _{j}\left[f(k, j)+\frac{d B^{*}(k)}{d k}(j-\sigma k)\right]
$$

Note that in the limit case, where there is no borrowing and $N=k$, and thus the constant discount rate $\theta$ holds we obtain the HJB-equation (10). The HJB-equation (11) can be written as

$$
B^{*}(k)=\max _{j} H^{-1}\left[f(k, j)+\frac{d B^{*}(k)}{d k}(j-\sigma k)\right]
$$

which is a standard dynamic form of a HJB-equation. Next, for the purpose of an example, let us specify $H(k, B)=B^{\kappa} \theta$ where, with $\kappa>1$ the interest payment is solely convex in $B$. We then have

$$
B^{*}(k)=\max _{j}\left[f(k, j)+\frac{d B^{*}}{d k}(j-\sigma k)\right]^{\frac{1}{\kappa}} \theta^{-\frac{1}{\kappa}}
$$

In the appendix 1 the equilibria of the HJB-equation (13) with $\kappa>1$ are shown and it is demonstrated that for $\kappa=1$ in (13) the same equilibria emerge as for (10). The algorithm to study the more general problem of equ. (11) is described in appendix 3.

Note that $B^{*}(k)$ in (13) for the case of $\kappa>1$ will be smaller than $V(k)$ in (10). There is an additional default cost to be paid which is not present in equ. (10), the integral of which will drive a wedge between the present value $V(k)$ and $B^{*}(k)$. So that $B^{*}(k)<V(k)$ will hold.

Employing our general form of a default premium ${ }^{24} H(k, B) \geq \theta B$ the creditworthiness $B^{*}(k)$ relates to the asset value of the firm for $B(t) \leq$ $B^{*}(k(t))$ as follows. Consider the equation

$$
\dot{B}=H(k, B)-f(k, j) .
$$

Multiplying by $e^{-\theta t}$ and using partial integration we find

$$
\int_{0}^{T} e^{-\theta t} f(k, j) d t=B(0)-e^{-\theta T} B(T)+\int_{0}^{T} e^{-\theta t}(H-\theta B) d t .
$$

Let us define the present value of the external finance premium - with initial value $(k, B)$ - by 


$$
\int_{0}^{\infty} e^{-\theta t}(H-\theta B) d t=V_{H}(k, B) .
$$

where we use the optimal investment rate $j$. Then for $T \rightarrow \infty$ we find

$$
V(k)=B(0)-\lim e^{-\theta T} B(T)+V_{H}(k, B)
$$

Note that we permit $B(t)$ to be negative. The term $V_{H}(k, B)$ would be equal to zero for the case $H(k, B)=\theta B .^{25}$

In particular, if $B(0)=B^{*}(k)$ we have

$$
V(k)=B^{*}(k)+V_{H}\left(k, B^{*}(k)\right)
$$

We want to point out how to compute $V(k)$ and its component parts. We can use the above statement to compute the solution to the optimal investment problem:

1. Compute $B^{*}(k)$, thereby find the optimal path $(k(t), B(t))$ which satisfies $B(t)=B^{*}(k(t))$.

2. Compute

$$
V_{H}(k, B)=\int_{0}^{\infty} e^{-\theta t}(H(k(t), B(t))-\theta B(t)) d t
$$

\section{Compute}

$$
V(k)=B^{*}(k)+V_{H}\left(k, B^{*}(k)\right) .
$$

In sum, the above three steps allow us to compute the creditworthiness, for the case $H(k, B)=\theta B$ where $V(k)=B^{*}(k)$ and for the case of an endogenous default premium $H(k, B)$, where for $H\left(k, B^{*}(k)\right)$ the creditworthiness will be less than $V(k)$. Whenever $B<B^{*}$ the value of the firm's assets can be represented by stocks and bonds permitting also a consumption stream for the owner of the stocks. Yet, as we will show in sect. 4.2 the firm's asset value may also be affected by the default premium.

In the context of the model (2)-(4) we can also explore the use of 'ceilings' in debt contracts and their impact on the present value of the firm. Indeed credit restrictions may affect the present value. Suppose the 'ceiling' is of the form $B(t)<C$, with $C$ a constant, for all $t$. Either $C>V(k)$, then the ceiling is too high because the debtor might be tempted to move close to the ceiling and then goes bankrupt if $B>V(k)$. If $C<V(k)$, then the firm 
may not be able to develop its full potentials, and thus face a welfare $\operatorname{loss}^{26}$. Those conditions obviously are of no practical use for debt control if we can not say when $B(t) \leq C$. The major tasks of our methods will be to compute the present value and thus the asset price of the firm $V(k)$ even for the case of endogenous credit cost as given in equ. (1).

Since the optimal investment strategy depends on the initial conditions of the firms, on the firms' capital stock, there may be thresholds that separate the optimal solution paths for $V(k)$ to different domains of attraction. For firms with lower capital stock then below the threshold it will be optimal for the firm to contract whereas large firms may choose an investment strategy to expand. We also will consider the case of debt for a constrained firm for which holds that $B(t) / k(t) \leq c$ with $c$ a constant and then study the asset price of the firm. Moreover, we can admit in our study various paths for the consumption stream, $c(t)$, and their impact on the present value curve $V(k)$ for our different model variants.

\section{Numerical Solution Methods}

A dynamic programming (DP) algorithm ${ }^{27}$ can be applied to solve the discounted infinite horizon optimal control problem of type (7)-(9). This is applicable when no restriction on the dynamics is present. For our model, this applies when the the model is linear, i.e., $H(k, B)=\theta B$ as in (9) and if in addition the constraint on $B$ is given by $\inf _{j} \sup _{t \geq 0} B(t)<\infty$, since in this case it follows from $(7)$ that $B^{*}(k)$ is easily obtained from $V(k)$ in $(2)$, namely from

$$
V(k)=\operatorname{Max}_{j} \int_{0}^{\infty} e^{-\theta t} f(k(t), j(t)) d t
$$

We will briefly describe the algorithm which goes back to Capuzzo Dolcetta (1983), Falcone (1987) and Grüne (1997). For details and for a mathematically rigorous convergence analysis we refer to the work by Bardi and Capuzzo Dolcetta (1997) and to Grüne, Metscher and Ohlberger (1999).

In the first step, the continuous time optimal control problem is replaced by a first order discrete time approximation given by

$$
V_{h}(k)=\underset{j}{\operatorname{Max}} J_{h}(k, j), \quad J_{h}(k, j)=h \sum_{i=0}^{\infty}(1-\theta h)^{i} f\left(k_{h}(i), j_{i}\right)
$$

where $k_{h}$ is defined by the discrete dynamics

$$
k_{h}(0)=k, \quad k_{h}(i+1)=k_{h}(i)+h\left(j_{i}-\sigma k_{h}(i)\right)
$$


and $h>0$ is the discretization time step. Note that $j=\left(j_{i}\right)_{i \in \mathbb{N}_{0}}$ here denotes a discrete control sequence.

The optimal value function is the unique solution of the discrete HamiltonJacobi-Bellman equation

$$
V_{h}(k)=\operatorname{Max}_{j}\left\{h f\left(k, j_{0}\right)+(1-\theta h) V_{h}\left(k_{h}(1)\right)\right\}
$$

where $k_{h}(1)$ denotes the discrete solution corresponding to the control $j$ and initial value $k$ after one time step $h$. Abbreviating

$$
T_{h}\left(V_{h}\right)(k)=\operatorname{Max}_{j}\left\{h f\left(k, j_{0}\right)+(1-\theta h) V_{h}\left(k_{h}(1)\right)\right\}
$$

the second step of the algorithm now approximates the solution on a grid $\Gamma$ covering a compact subset of the state space, i.e., a compact interval $[0, K]$ in our setup. Denoting the nodes of $\Gamma$ by $k^{i}, i=1, \ldots, P$, we are now looking for an approximation $V_{h}^{\Gamma}$ satisfying

$$
V_{h}^{\Gamma}\left(k^{i}\right)=T_{h}\left(V_{h}^{\Gamma}\right)\left(k^{i}\right)
$$

for each node $k^{i}$ of the grid, where the value of $V_{h}^{\Gamma}$ for points $k$ which are not grid points (these are needed for the evaluation of $T_{h}$ ) is determined by linear interpolation. We refer to the work cited above for the description of iterative methods. Note that an approximately optimal control law (in feedback form for the discrete dynamics) can be obtained from this approximation by taking the value $j^{*}(k)=j$ for $j$ realizing the maximum in (A10), where $V_{h}$ is replaced by $V_{h}^{\Gamma}$. This procedure in particular allows the numerical computation of approximately optimal trajectories.

In order to distribute the nodes of the grid efficiently, we make use of a posteriori error estimation. For each cell $C_{l}$ of the grid $\Gamma$ we compute

$$
\eta_{l}:=\underset{k \in C_{l}}{\operatorname{Max}_{l}}\left|T_{h}\left(V_{h}^{\Gamma}\right)(k)-V_{h}^{\Gamma}(k)\right|
$$

(more precisely we approximate this value by evaluating the right hand side in a number of test points). It can be shown that the error estimators $\eta_{l}$ give upper and lower bounds for the real error (i.e., the difference between $V_{h}$ and $V_{h}^{\Gamma}$ ) and hence serve as an indicator for a possible local refinement of the grid $\Gamma$. It should be noted that this adaptive refinement of the grid is very effective ${ }^{28}$ for detecting thresholds, because the optimal value function typically fails to be differentiable in these points, resulting in large local errors and consequently in a fine grid.

For the more general model, i.e., if there is a default premium as defined by $H(k, B)$ in $(1)$ and/or restrictions of the type $B / k \leq c$, the above DPalgorithm unfortunately is not applicable. Even though in certain cases a 
HJB-equation for a discrete time version of the problem is available, it is not clear whether the full discretization procedure described above leads to a valid and convergent approximation of the asset price and the present value borrowing constraint.

Hence we propose a different approach for the solution of this problem, based on a set oriented method for the computation of domains of attraction. The method relies on the following observation: For a given compact interval ${ }^{29}[0, K]$ for the capital stock $k$ one sees that there exists a constant $c^{*}>0$ such that $B^{*}(k) \leq c^{*}$ for all $k \in[0, K]$. We here denote $B^{*}(k)$ as the borrowing constraint of the firm. Hence, for $k \in[0, K]$ the condition $\sup _{t \geq 0} B(t)<\infty$ can be replaced by

$$
\sup _{t \geq 0} B(t)<c^{*}
$$

Hence both this constraint and the constraint $B(t) \leq c k(t)$ can be expressed as

$$
B(t) \leq d(k(t)) \text { for all } t \geq 0
$$

for some suitable function $d$. In other words, the set of all initial values $\left(k_{0}, B_{0}\right)$ for which this constraint is violated is given by

$$
D=\left\{\begin{array}{l|l}
\left(k_{0}, B_{0}\right) & \begin{array}{l}
\text { there exists } T>0 \text { such that } B(t(j)) \geq d(k(t(j))) \\
\text { for all } j \text { and some } t(j) \in[0, T]
\end{array}
\end{array}\right\}
$$

and the curve $B^{*}(k)$ is exactly the lower boundary of $D$. For details of how the domains of attraction are computed, see appendix 2. Equipped with the above two algorithms the firm's asset value and thus the maximum debt capacity $B^{*}$ can be computed.

\section{$5 \quad$ Results of the Numerical Study}

Next, we present numerical results for our debt control problem obtained for our case with a risk-free interest rate, and the case of a default premium. In the latter cases we have to specify $H(k, B)$. For both cases we specify the firms' technology parameters to be the same namely $\sigma=0.15, A=0.29$, $\alpha=1.1, \beta=2, \gamma=0.3$ and $\theta=0.1$, so that results do not differ because of different technology parameters. ${ }^{30}$ The distinct results that we obtain should therefore solely arise from the issuance of the firm's risky debt. The remaining parameters are specified below. ${ }^{31}$

As for the numerical procedure, all examples were computed for different $k^{\prime} s$ in the compact interval $[0,2]$ with control range $j \in[0,0.25] .{ }^{32}$ For our 
dynamic programming algorithm, discussed above, we have used the numerical time step $h=0.05$ and an initial grid with 39 nodes. The final adapted grid consisted of 130 nodes. The range of control values was discretized using 101 equidistributed values. For the algorithm of appendix 2 that computes domains of attraction we used the time step $h=0.5$, in order to generate the discrete time model $\Psi$ we used a highly accurate extrapolation method. For this algorithm the range of control values was discretized using 51 equidistributed values. The domain covered by the grid was chosen to be $[0,2] \times[0,3]$ where the upper value $\bar{B}=3$ coincides with the value $c^{*}=3$ used in order to implement the restriction $\sup _{t \geq 0} B(t)<\infty$. The initial grid was chosen with 1024 cells, while the final adapted grids consisted of about 100000 up to 500000 cells, depending on the example. For this algorithm the figures below always show the set $E_{\Gamma}$ which approximates the present value curve $V(k)$. Recall that the width of this set gives an estimate for the spatial discretization error.

\subsection{Borrowing at the Risk-free Rate}

In our benchmark case, debt is issued but with zero default premium paid by the firm so that we have as credit cost $H(k, B)=\theta B$. In this case we can use the DP algorithm of section 4 in order to solve the discounted infinite horizon problem (7)-(9). Figure 2 shows the corresponding optimal value function representing the present value curve, $V(k)$, (upper graph) and the related optimal control, the investment decision, in feedback form (lower graph). The present value curve represents the asset value of the firm for initial conditions $k(0)$.

Figure 2 about here:

\section{Optimal value function and optimal investment}

The debt control problem is solved whenever debt is bounded by the firm's asset value, so that we have $V-B \geq 0$. In this case, however, the optimal investment strategy is not constrained and thus the asset value which represents the maximum debt capacity $B^{*}$, is obtained by a solution for an unconstrained optimal investment strategy, represented by the value function in Figure 2. Note however, that for our parameters the model does not necessarily have a unique steady state equilibrium. There can be multiple domains of attraction depending on the initial capital stock size, $k$. The multiple steady states of the above model are computed in appendix 1. As we can observe from figure 2 , there is a threshold, $s$, at $k^{+}=0.267$ which is clearly visible in the optimal control law, which is discontinuous at this 
point. Thus, the dynamic decision problem of the firm faces a discontinuity. For firms with initial values of the capital stock $k(0)<k^{+}$the optimal trajectories tend to $k^{*}=0$, for initial values of the capital stock $k(0)>k^{+}$ the optimal trajectories tend to the domain of attraction $k^{* *}=0.996$. Yet, for all of those different initial conditions debt dynamics is bounded as long $V-B \geq 0$, which allows the firms equity holder to exercise the option of refining the debt and to obtain an equity value of $S=V-B$.

Figure 2 also shows the sequence of investment decisions, in a neighborhood of the threshold for the given initial capital stock. There is a discontinuity and thus a jump in the investment strategy of the firms, which is clearly observable. Investment of a firm to the left of $k^{+}$is lower than $\sigma k$ and makes the capital stock shrinking whereas investment of a firm to the right of $k^{+}$ is larger than $\sigma k$ and let the capital stock increase. At $k^{+}$investment of the firm then jumps. ${ }^{33}$

\subsection{Borrowing with a Default Premium}

For the more general case where a default premium is to be paid we had suggested the following function to represent risk premia:

$$
H(k(t), B(t)))=\frac{\alpha_{1}}{\left(\alpha_{2}+\frac{N(t)}{k(t)}\right)^{\mu}} \theta B(t)
$$

For the model (2)-(4) with a risk premium included in the firms' borrowing cost it is not possible to transform the model into a standard infinite horizon optimal control problem of a firm since debt, or net worth, is now an additional constraint on the optimization problem. Hence we will use the algorithm for the computation of domains of attractions from appendix 2 and undertake experiments for different shapes of the credit cost function representing different alternative functions for the risk premium. An important class of functions for risk premia is defined by the steepness of the slope defined by the parameter $\alpha_{2} \cdot{ }^{34}$

For the above risk premium function we specify $\mu=2$. Taking into account that we want $\theta$ to be the risk-free interest rate, we obtain the condition $\alpha_{1} /\left(\alpha_{2}+1\right)^{2}=1$ and thus $\alpha_{1}=\left(\alpha_{2}+1\right)^{2}$. Note that for $\alpha_{2} \rightarrow \infty$ and $0 \leq B \leq k$ one obtains $H(k, B)=\theta B$, i.e., the model from the previous section. 35

Figure 3 shows the respective present value curves $V(k)=B^{*}(k)+$ $V_{H}(k, B)$ under the condition $\sup _{t \geq 0} B(t)<\infty$ for $\alpha_{2}=100,10,1, \sqrt{2}-1$ (from top to bottom) and the corresponding $\alpha_{1}=\left(\alpha_{2}+1\right)^{2}$.

Figure 3 about here: Present value curve $V(k)$ for different $\alpha_{2}$ 
For $\alpha_{2}=100$ firm's asset value and the trajectories on the curve $V(k)$ show almost the same behavior as the ones in the previous section: There exists a threshold (now at $k^{+}=0.32$ ) and two stable domains of attraction at $k^{*}=0$ for all initial capital sizes and we have $k^{* *}=0.99$. For this as well as the other trajectories hold that the value function and thus the asset value of the firm is smaller the larger the default risk resulting from low net worth. Thus, a state dependent default risk has the same effect on firm value as a higher discount rate in a standard q-theory of investment. The debt capacity curve, $B^{*}$, moves down due to higher credit cost (higher default risk) and if the debt rises such that the debt constraint curve $B^{*}(k)$ is reached the net income of the firm shrinks to zero so that $V-B=0$ and no equity value claim on the net income stream of the firm can be supported.

From the figure 3 one can observe that, as our study in sect. 3 predicts, the constraint on the maximum debt claim to the firm $B^{*}(k)=V(k)$ curve moves down with a steeper slope of the risk premium function, equ. (1), which gives rise to a larger loss $V_{H}\left(k, B^{*}\right)$ in equ. (14).

\begin{tabular}{cccc}
\hline$\alpha_{2}$ & 100 & 10 & $\sqrt{2}-1$ \\
\hline$V_{H}\left(k, B^{*}(k)\right)$ & 0.041 & 0.274 & 1.140 \\
$B^{*}(k)$ & 2.477 & 2.214 & 1.273 \\
$V(k)$ & 2.518 & 2.488 & 2.410 \\
$V(k)$ for $\theta B$ & 2.523 & 2.523 & 2.523
\end{tabular}

Table 1: Optimal values

In order to evaluate the extent to which a value loss occurs, due to the risk premium of equ. (1), we computed the component parts of $V(k)$ for different slopes of the risk premium function $H(k, B)$. Note again that hereby the lower $\alpha_{2}$ represents a higher risk premium. In table 1, the values are given for $k_{0}=2$. The last row represents the benchmark case where we have computed the $V(k)$ for linear function $\theta B$, the other rows represent the case $H(k, B)$.

In Figure 4 the value $V(k)$, left figure, and the value loss $V_{H}(k)$, right figure, for different initial values and $\alpha_{2}=100$ and $\alpha_{2}=\sqrt{2}-1$ are shown. In the left figure, for reasons of comparison, the benchmark case for the linear function $\theta B$ is also shown, which, however, is almost undistinguishable from the curve for $\alpha_{2}=100$. As observable from our two figures the value $V(k)$ slightly decreases with rising risk premium (falling $\alpha_{2}$ ), left figure, and the value loss, $V_{H}(k, B)$, substantially increases (the debt capacity, $B^{*}(k)$, substantially decreases), right figure. The results clearly show the nonlinear effect of the risk premium on firm's asset value and maximum debt value 
$B^{*}(k)$. Of course, for any actual $B(k)$ here too it holds again that the value of stocks is $S(k)=V(k)-B(k)$. The reduction of firm's asset value through the debt issuance comes from the fact that firms now face a constrained optimization problem, through which, since their sequence of optimal investment strategy is constrained, asset value is reduced. ${ }^{36}$

Figure 4 about here:

\section{Value $V(k)$ (left) and Value loss $V_{H}(k)$ (right) for Different Endogenous Credit Cost}

The next figure, figure 5 , shows of how the choice of $\alpha_{2}$ affects the value $V(k)$ and the maximum debt capacity $B^{*}(k)$, evaluated at $k=2$. The parameter $\alpha_{2}$ determines how much the credit cost grows when the debtcapital ratio $B / k$ grows. In the limit for $\alpha_{2} \rightarrow \infty$ we obtain the linear credit $\operatorname{cost} \theta B$ while for decreasing $\alpha_{2}$ the risk premium becomes higher, hence $H(k, B)$ becomes steeper for fixed $B$ and growing ratio $B / k$.

Figure 5 shows that, as expected, the maximum debt capacity $B^{*}(k)$ decreases monotonically as $\alpha_{2}$ becomes smaller. The same happens for the value $V(k)$, however, for larger values of $\alpha_{2}$ this decrease of the firm's value is almost neglegible, i.e., if the credit cost is close to the risk free rate it needs a substantial increase of the credit cost. (in order to reduce the maximum capacity $B^{*}(k)$ and the asset value of the firm $V(k)$.

Figure 5 about here:

$$
B^{*}(k) \text { (left) and } V(k) \text { (right) at } k=2 \text { for varying } \alpha_{2}
$$

Yet, note that the dependence between all these values is highly nonlinear. It is rather difficult to visualize the relationship between credit cost and present value in general. In order to give an intuition about the relationship between these quantities, for selected values of $\alpha_{2}$ and $k=2$ in the following table we show the increase of the interest rate at the point $\left(k, B^{*}(k)\right)$, i.e., the relation $H(k, B) /(\theta B)$ and the decrease of the value $V(k)$, both in percent.

\begin{tabular}{rrr}
\hline$\alpha_{2}$ & increase of interest rate & decrease of $V$ \\
\hline 100 & $1.24 \%$ & $0.16 \%$ \\
50 & $2.45 \%$ & $0.20 \%$ \\
10 & $11.67 \%$ & $1.38 \%$ \\
3 & $30.55 \%$ & $5.51 \%$
\end{tabular}

Table 2: Increase of credit cost vs. decrease of value $V$ 
In table 2 numerical results are reported to what extent a certain percent of an increase in the credit cost would cause a certain percent fall in the value $V(k)$. This is undertaken for a fixed value of the capital stock $k=2$. The percent increases in interest rate of $1.24 \%$ in the table 2 for example means that the default risk causes the interest rate to rise from $\theta=0.1$, the risk free interest rate, to $H(k, B)=0.1124$, causing a fall of the asset value of the firm by 0.16 percent. Note that the parameter of our credit cost function of equ. (1) are chosen in such a way so as to have only slight increases in default premia with rising default risk. The cases shown in table 2 above represent, for example, an increase of the credit cost from $\alpha_{2}=\infty$ with a credit cost $\theta=0.1$, to $\alpha_{2}=3$, with a credit cost of 0.13055 . Yet, in the latter case the asset value of the firm is predicted to fall by 5.51 percent. We thus can conclude that the decrease of the asset value of the firm, caused by higher default premia, is of quantitative importance.

Next let us consider the debt control problem for different regions of the capital stock $k$. This has already been shown in figure 3 above. As concerning thresholds, the jump in investment, for the above discrete values occurs with large $\alpha_{2}$. With smaller values of $\alpha_{2}$ than 100, somewhere, there is no jump observable and there exists only one domain of attraction at $k^{*}=0$ which is stable. Further simulations have revealed that for decreasing values of $\alpha_{2} \leq 100$ the threshold value $k^{+}$increases (i.e., moves to the right) and the stable equilibrium $k^{* *}$ decreases (i.e., moves to the left), until they meet at about $\alpha_{2}=31$.

Then for all smaller values of $\alpha_{2}$ there exists just one equilibrium at $k^{*}=0$ for all capital stock sizes which is stable. The reason for this behavior lies in the fact that for decreasing $\alpha_{2}$ credit becomes more expensive, hence for small $\alpha_{2}$ it is no longer optimal for the firm - with any size of the capital stock - to borrow large amounts and to increase the capital stock for a given initial size of the firm, instead it is optimal to shrink the capital stock and to reduce the stock of debt $B(t)$ to 0 . Thus, with small $\alpha_{2}$ and steep risk premia, it is for any firm size, i.e. for any initial capital stock, optimal to shrink the capital stock.

\subsection{Debt Ceilings and Asset Value}

For the case of a risk premium given by $H(k, B)$ from $(1)$ with $\alpha_{2}=100$ we now test a different criterion for the debt ceiling and its impact on the investment decision and firm value: instead of $\sup _{t \geq 0} B(t)<\infty$ we impose a stronger restriction, namely $B(t) / k(t) \leq c$ for some constant $c$. This presumes that the creditors impose a debt ceiling for the firm which has been asumed in recent literature on imperfect capital markets. Again we use the 
algorithm from appendix 2. Figure 6 shows the respective curves for the restriction $\sup _{t \geq 0} B(t)<\infty$ and for the ratio-restriction with $c=1.2$ and $c=0.6$ (from top to bottom). In addition, the restriction curves $B=c k$ are shown with dots for $c=1.2$ and $c=0.6$.

Figure 6 about here:

Present value curve $V(k)$ for different debt ceilings, $H(k, B)$ from ( 1)

For $c=0.6$ the firm asset value curve $V(k)$ coincides with the "restriction curve" $B(k)=c k$; in this case the curve $(k, V(k))$ is no longer invariant for the dynamics, ${ }^{37}$ i.e., each trajectory $B(t)$ with $B(t) \leq V(k(t))$ leaves the curve $(k, V(k))$ and eventually $B(t)$ tends to $-\infty$. For $c=1.2^{38}$ the curves $B^{*}(k)$ and $B=c k$ coincide only for capital stock size $k \geq 1.46$. Overall, the solution of the debt control problem by imposing debt ceilings is that the debt becomes controllable and can be steered to zero with low debt ceilings but the firm's asset value, $V(k)$ also shrinks.

As concerns the threshold and the jump in investment here one observes the same steady stock equilibria $k^{*}$ and $k^{* *}$ and threshold $k^{+}$as for the suprestriction (see sect. 5.2), however, in addition to these here a new threshold appears at $k^{++}=1.54$. For initial values of capital stock $(k, V(k))$ with $k^{+}<k<k^{++}$the firm expands and tends to the stable domain of attraction $k^{* *}$, while for firms with initial capital stock $k>k^{++}$the behavior is the same as for $c=0.6$, i.e., the corresponding trajectories leave the curve $V(k)$ and eventually $B(t)$ tends to zero. ${ }^{39}$

In sum we can observe that introducing low enough debt ceilings may, as in the case of $c=0.6$, decrease the default risk, keeping the solvency of the firm, but the present value and thus the asset price of the firm will decrease too.

\section{Conclusions}

In the paper we study the firm's asset value in the context of a dynamic decision problem where firms can borrow from the credit market for investment and where there is a risk premium which may be state dependent and the firms may face debt ceilings. Firms may be heterogeneous with respect to certain characteristics relevant for the credit market. Building on a production oriented asset pricing model we can show that those characteristics impact the firm's risk premia, the firm's sequence of investment decision as well as

the firm's asset value. If risk premia, debt capacity (creditworthiness) ${ }^{40}$ and asset value are endogenous resulting from a constrained investment strategy 
then the asset value of firms cannot be taken as exogenously when firms securities such as stocks and bonds are priced. We use modern computational methods to solve the intertemporal decision problem and to compute the asset value of firms with endogenous risk premia. We also explore the impact of different shapes of the risk premium function and debt ceilings on the investment strategy, which may be discontinuous, and on the firm's asset value. If multiple domains of attraction exist we compute thresholds separating different domains of attraction of the capital stock and the corresponding asset price movements. We employ numerical dynamic programming and a set oriented algorithm solve the complicated optimization problems and the dynamics of the asset value of the firm. 


\section{Appendix}

In this appendix we present the solution technique of how to find the equilibria of the HJB-equations (10) and (11). Moreover, we describe an algorithm which enable us to compute the asset price of the firm for the HJB equation of a type such as (13) which will give us the present value borrowing constraint, the discontinuities in the decision variable and thresholds separating different domains of attraction for initial capital stocks. While the DP-algorithm as proposed in sect. 4 and the one proposed below are of quite different nature,

a common feature of both is the adaptive discretization of the state space which leads to high numerical accuracy with moderate use of memory.

\subsection{Computation of the Steady State Equilibria}

The HJB-equation (10) for our problem reads

$$
\theta V=\max _{j}\left[k^{\alpha}-j-j^{2} k^{-\gamma}+V^{\prime}(k)(j-\sigma k)\right]
$$

We can compute the steady state equilibria and the rough shape of value function and thresholds in three steps

Step 1: Compute the steady state candidates

For the steady state candidates, for which $0=j-\sigma k$ holds, we obtain:

$$
\begin{gathered}
V(k)=\frac{f(k, j)}{\theta} \\
V^{\prime}(k)=\frac{f^{\prime}(k, j)}{\theta}=\frac{\frac{\partial}{\partial k}\left(k^{\alpha}-\sigma k-\sigma^{2} k^{2-\gamma}\right)}{\theta}
\end{gathered}
$$

Using the information of (A2)-(A3) in (A1) gives, after taking the derivatives of (A1) with respect to $j$, the steady states for the stationary HJB equation:

$$
-1-2 j k^{-\gamma}+\frac{\alpha k^{\alpha-1}-\sigma-\sigma^{2}(2-\gamma) k^{1-\gamma}}{\theta}=0
$$

Note that hereby $j=\sigma k$. Given our parameters the equation admits three steady states.

Step 2: Derive the differential equation $V^{\prime}$ 
Next, we derive differential equation $\mathrm{V}^{\prime}$ by taking

$$
\frac{\partial \theta V}{\partial j}=0
$$

We obtain

$$
-1-2 j k^{-\gamma}+V^{\prime}(k)=0
$$

Note that $V^{\prime}(k)$ represents Tobin's q. So we have $q-1=2 j k^{-\gamma}$ or $j=\frac{(q-1) k^{\gamma}}{2}$ which is familiar from Tobin's investment theory. Yet, note that out of the steady state equilibria we do not have any information on $V^{\prime}(k)$. Solving for the optimal $j$ and using the optimal $j$ in (A1) we get

$$
V^{\prime}=1+2 \sigma k^{1-\alpha} \pm \sqrt{\left(1+2 \sigma k^{1-\alpha}\right)^{2}+4 \delta k^{-\alpha} V+k^{\gamma-\alpha}-6}
$$

To solve (A5) we could start the iteration with steady states as initial conditions. For $e$, a steady state, we get as initial value for the solution of the differential equation (A3):

$$
\begin{aligned}
V_{0} & =\int_{0}^{\infty} e^{-\delta t} f(e, j) d t \\
V_{0} & =\frac{1}{\delta} f(e, j)
\end{aligned}
$$

Step 3: Compute the global value function by taking

$$
V(k)=\max _{i} V_{i}
$$

where $V(k)$ is the outer envelop of the piece-wise value function.

If the HJB-equation (13) holds with $H(B)=\theta B^{\kappa}$, the external finance premium, depends on the liability of the firm. This extension is presented in Semmler and Sieveking (2000) and Grüne, Semmler and Sieveking (2003). For $H(B)=\theta B^{\kappa}$ for $\kappa \geq 1$ it leads to the following equation for candidates of equilibrium steady states

$$
1+2 j k^{-\gamma}=\frac{\alpha k^{\alpha-1}-\sigma-\sigma^{2}(2-\gamma) k^{1-\gamma}}{\theta \kappa\left(k^{\alpha}-\sigma k-\sigma^{2} k^{2-\gamma}\right)^{(\kappa-1) / \kappa}}
$$

Note that the steady state candidates are the same as in (A4) if in (A6) $\kappa=1$ holds. For details of the solution and the use of the HJB-equation to solve for thresholds, see Grüne, Semmler and Sieveking (2003). 


\subsection{Computing Domains of Attraction}

The set $D$ in sect. 4 is what is called a robust domain of attraction of the set $A=\left\{(k, B) \in \mathbb{R}^{2} \mid B \geq d(k)\right\}$ and we will here give a brief description of an algorithm for the computation of such sets, for details we refer to Grüne (2001) and Chapter 7 of Grüne (2002).

We we consider a first order discrete time approximate model, now both for $k$ and $B$ given by the Euler discretization ${ }^{41}$

$$
\begin{aligned}
k_{h}(i+1) & =k_{h}(i)+h\left(j_{i}-\sigma k_{h}(i)\right) \\
B_{h}(i+1) & =B_{h}(i)+h H\left(k_{h}(i), B_{h}(i)\right)-h f\left(k_{h}(i), j_{i}\right)
\end{aligned}
$$

and abbreviate the right hand side by $\Psi(k, B, j)$. Just as above, for the space discretization we use a grid $\Gamma$, now covering a two-dimensional rectangular domain $[0, K] \times[0, \bar{B}]$. For each cell $C_{l}, l=1, \ldots, Q$ of the grid we use a collection of test points $x_{l}^{i}=\left(k_{l}^{i}, B_{l}^{i}\right), i=1, \ldots, N$ in order to compute the set image

$$
\Phi\left(C_{l}, \bar{\jmath}\right)=\bigcup_{m} C_{m} \text { for all } m \in\{1, \ldots, Q\} \text { with } \Psi\left(k_{l}^{i}, B_{l}^{i}, j^{i}\right) \in C_{m}
$$

where $\bar{\jmath}=\left(j^{1}, \ldots, j^{N}\right)$ is a vector of $N$ control values associated to the $N$ test points. For a sequence $\left(\bar{\jmath}_{i}\right), i=0,1,2, \ldots$ of such control vectors we can iterate the map $\Phi$ and we denote the resulting iterated map by $\Phi_{i}\left(C_{l},\left(\bar{\jmath}_{i}\right)\right)$. Now we can define the following three sets

$$
\begin{aligned}
& D_{\Gamma}=\bigcup_{m} C_{m} \text { for all } m \text { with } \Phi_{i}\left(C_{m},\left(\bar{\jmath}_{i}\right)\right) \subseteq A \text { for all }\left(\bar{\jmath}_{i}\right) \text { and some } i \\
& B_{\Gamma}=\bigcup_{m} C_{m} \text { for all } m \text { with } \Phi_{i}\left(C_{m},\left(\bar{\jmath}_{i}\right)\right) \cap A=\emptyset \text { for some }\left(\bar{\jmath}_{i}\right) \text { and some } i \\
& E_{\Gamma}=\bigcup_{m} C_{m} \text { for all } m \text { with } C_{m} \nsubseteq D_{\Gamma} \text { and } C_{m} \nsubseteq E_{\Gamma}
\end{aligned}
$$

These sets are easily computed by a dynamic programming type iteration and under appropriate conditions it can be shown that the set $D_{\Gamma}$ approximates $D$, the set $B_{\Gamma}$ approximates $D^{c}$ (the complement of $D$ ) and the set $E_{\Gamma}$ approximates $\partial D$ (the boundary of $D$ ), which in our case is exactly the curve $B^{*}(k)$. It turns out that for obtaining more and more accurate approximations (with respect to the space discretizations) it is sufficient to increase the accuracy on the set $E_{\Gamma}$, i.e., to refine the cells $C_{m} \subseteq E_{\Gamma}$.

While the convergence analysis in the general case is rather complicated and depends on certain properties of $D$, for our problem we can use the 
fact that the boundary $\partial D$ is given by the curve $B^{*}(k)$ which is monotone increasing in $k$. Hence, if we use a rectangular grid, and choose the test points in each cell to be the 4 corners of this rectangular cell, we obtain that if a cell $C_{m}$ intersects both $D$ and $D^{c}$, then there exist test points $x_{m}^{k_{1}}$ and $x_{m}^{k_{2}}$ in this set such that $x_{m}^{k_{1}} \in D$ and $x_{m}^{k_{2}} \notin D$. Consequently, the iterated cell image $\Phi_{i}$ cannot be contained in $A$ for all $\left(\bar{\jmath}_{i}\right)$ (implying that $C_{m} \not D_{\Gamma}$ ) but it intersects $A$ for each $\left(\bar{\jmath}_{i}\right)$ (implying that $C_{m} \nsubseteq B_{\Gamma}$ ). Thus, if a cell $C_{m}$ intersects both $D$ and $D^{c}$ then we obtain that $C_{m} \subseteq E_{\Gamma}$ which finally yields that the set $E_{\Gamma}$ always covers the boundary $\partial D$ and hence gives an approximation of the curve $B^{*}(k)$ whose accuracy is equal to the width of the set $E_{\Gamma} \cdot{ }^{42}$

Since the problem which is solved by this algorithm is not a classical optimal control problem (though it can be interpreted as an optimal control problem for the set valued dynamics) it is not possible to obtain optimal trajectories with respect to some given functional. However, it is not too difficult to prove that the boundary of a domain of attraction $D$ is weakly invariant (i.e., for an initial value on the boundary $\partial D$ we can always find trajectories that remain on $\partial D$ for all future times), provided it is a "proper" domain of attraction, i.e., its boundary does not intersect with the boundary of $A$. Due to this fact, for each initial value $(k, B) \in B_{\Gamma}$ (recall that this set forms our numerical approximation of the set $\left\{(k, B) \mid B \leq B^{*}(k)\right\}$ of subcritical initial values) we can compute a control sequence $j_{i}$ realizing a (discrete time) trajectory for which $B_{h}(i)$ remains bounded for all times $i \geq 0$ and for initial values on the upper part of the boundary $\partial B_{\Gamma}$ we can even expect to find trajectories that stay on this upper part of $\partial B_{\Gamma}$ for all future times, i.e., they are (up to the numerical error) of the form $\left(k(t), B^{*}(k(t))\right.$. The limiting behavior of these trajectories can then be used for the detection of the thresholds, separating different domains of attraction, and it turns out that this procedure yields very good results. 


\section{Endnotes}

${ }^{1}$ See Hanke (2003, ch. 2) where this is shown using option prices with endogenous stock price process.

${ }^{2}$ For details see Merton (1974).

${ }^{3}$ Empirical studies on Tobin's q and investment can be found in Abel and Blanchard (1986), Cochrane (1991), Abel and Eberly (1994) and Lettau and Ludvigson (2002), in particular the latter state that perfect capital markets are hereby presumed.

${ }^{4}$ See Rouwenhorst, (1995).

${ }^{5}$ We are grateful for comments on this issue by a referee of the journal.

${ }^{6}$ For asset pricing with all equity finance of firms, see Grüne and Semmler (2003). As has been argued since long, in the case of an all equity financed firm the optimization problem of the firm and the one from the consumption based asset pricing theory should give the same results.

${ }^{7}$ See, for example, Duan, Ganthier, Simonato and Zaanoun (2002). The survey of empirical methods is given of how to estimate the asset value of the firm from time series of its equity value.

${ }^{8} \mathrm{~A}$ stochastic version of such a dynamic programming algorithm is used in Grüne and Semmler (2002) where a consumption based asset pricing model is solved.

${ }^{9}$ see Hankel (2003).

${ }^{10}$ See Tobin (1969).

${ }^{11}$ Hayashi (1982) presents conditions under which average and marginal q are equal.

${ }^{12}$ Numerous tests on investment and the average and marginal $\mathrm{q}$ have been undertaken. See, for example, Abel and Blanchard (1986) and recently Lettau and Ludvigson (2002) and the discussion of the recent empirical literature therein. In consumption based asset 
pricing models the price of an asset purchases a dividend stream for consumption whereby the discount factor is derived from a long term objective of the asset holder, namely the subjective discount factor times the growth rate of the marginal utility in consumption, for a theoretical analysis see Cochrane (2001), ch. 1 and for a numerical study, see Grüne and Semmler (2003).

${ }^{13}$ Investment models with credit market borrowing from imperfect capital markets can be found in Townsend (1979), Kiyotaki and Moore (1997), Bernanke, Gertler and Gilchrist (1999) and Miller and Stiglitz (1999). In these models the impact of imperfect credit market borrowing and debt dynamics on economic activity is studied. See also Flaschel, Franke and Semmler (1997, ch. 12) for the impact of finance constraints on investment. Yet in those models the implications of debt financing on firms' asset pricing and creditworthiness has not been sufficiently explored.

14 This literature originates in the seminal work by Townsend (1979).

${ }^{15} \mathrm{We}$, in order to simplify matters, do not employ a stochastic version but rather employ a deterministic framework. A stochastic version is discussed in Sieveking and Semmler (1999) and Grüne and Semmler (2003). Recent work has been undertaken by nesting credit market imperfections and endogenous borrowing cost more formally in intertemporal models, see Carlstrom and Fuerst (1997), Cooley and Quadrini (1998) and Krieger (1999).

${ }^{16}$ As Gomes et al (2002) show for a large class of models one can expect the external finance premium indeed to be equal to the premium necesssary to compensate lenders for the default risk. Gomes et al (2002) measure the default risk by the spread of corporate bonds and T-bills. Another proxy is the relative size of external finance to capital, see Gomes et al (2002).

${ }^{17}$ Another way to state the risk premium, and thus the risk structure of interest rates if there is debt with different maturity, is $R(\tau)-\theta$ with $R(\tau)$ the yield to maturity $\tau$, see 
Merton (1974). Hereby $R(\tau)$ is then implicitly defined as $e^{-R(\tau) \tau}=\frac{F(V, \tau)}{B}$.

${ }^{18}$ Note also that for each firm bonds with different maturity could have different risk premia which we will, however, disregard here.

${ }^{19}$ For details of such a model see Sieveking and Semmler (1999).

${ }^{20}$ Note that in order to recover the usual optimization problem for linear credit cost, we state our optimization problem in a way so as to include the limit case when there is a linear credit cost. Yet our numerical procedure (as briefly summarized in appendix 2) can solve the difficult problem when there are state dependent default premia.

${ }^{21}$ The model can also be interpreted as written in efficiency labor, therefore $\sigma$ can represent the sum of the capital depreciation rate, and rate of exogenous technical change. Note that in (4) a consumption stream could be included. In the study by Grüne, Semmler and Sieveking (2003) such a consumption stream is treated.

22 As aforementioned in computing the present value of the future net income we do not have to assume a particular fixed interest rate, but the present value, $V(k)$, will, for the optimal investment decision, enter as argument in the credit cost function $H(k(t), V((k(t))$.

${ }^{23}$ Note, however, that in the first two strands of literature mentioned in sect. 2 there is usually a stochastic version used where in the HJB equation then, using Ito's lemma, also the derivatives of $V$ with respect to the random disturbance would appear in the HJB equation.

${ }^{24}$ For more details of the subsequent derivations, see Grüne, Semmler and Sieveking (2002).

${ }^{25}$ Note that in practise the discount rate $\theta$ is often approximated by taking a weighted average cost of capital (WACC) composed of the weighted average of equity return and bond return, see Benninga (2000, ch. 2), see also Abel and Blanchard (1986).

26 See Section 5.3 below.

${ }^{27}$ For a further discussion of the dynamic programming algorithm and more detailed appli- 
cations in economics, see Grüne and Semmler (2002).

${ }^{28}$ Actually, for the one-dimensional problem at hand it is possible to compute rather accurate approximations $v_{h}^{\Gamma}$ also with equidistributed grid points. In higher dimensions the computational advantage of adaptive gridding is much more obvious, see, e.g., the examples in Grüne (1997) or Grüne et al. (1999).

${ }^{29}$ In any numerical method we must restrict ourselves to a compact computational domain, hence this restriction is natural in this context.

${ }^{30}$ We want to note that the technology parameter $\alpha$ does not need to be as high as we here assumed to obtain multiple equilibria, sufficient nonlinearity in adjustment costs will also generate that result.

${ }^{31}$ Note that we, of course, could choose another source of heterogeneity of firms, namely by assuming different technology parameters for firms. This might be another line of research which we will not pursue here.

${ }^{32}$ In all our experiments larger control ranges did not yield different results.

${ }^{33}$ In either case debt is controllable for $V-B \geq 0$. As mentioned in section 4 , in our DP algorithm the grid about the threshold point, is particularly refined where the value function at this point, results in a non-differentiable value function and hence in large local errors.

${ }^{34}$ As we will show, when presenting our numerical results, the parameter $\alpha_{2}$ generates only moderate steepness of the credit cost curve.

${ }^{35}$ For small values of $\alpha_{2}$ it turns out that the present value curve satisfies $V(k)<k$, hence this change of the formula has no effect on $V(k)$.

${ }^{36}$ Note that this effect could not be seen in Merton (1974) and Modigliani and Miller (1958) and since the firm's asset value in their studies, is exogenously given.

${ }^{37}$ As mentioned in appendix 2 the boundary of the domain of attraction $D=\{(k, B) \mid B>$ 
$V(k)\}$ of the set $A=\{(k, B) \mid B \geq c k\}$ is invariant for the trajectories, provided $\partial D$ and $\partial A$ do not intersect. Here we have $V(k)=c k$, i.e., the boundaries $\partial D$ and $\partial A$ do intersect (they even coincide) and consequently we cannot expect invariance.

38 This curve is difficult to see because it coincides with the curve for $\sup _{t \geq 0} B(t)<\infty$ for small $k$ and with the restriction curve $B=c k$ for large $k$.

39 The simulation are halted at zero, but we would like to report if continued the $B(t)$ curve becomes negative and tends to $-\infty$.

${ }^{40}$ Our above analytical study of the debt control problem and suggests some methods of how to empirically evaluate sustainable debt, see Semmler (2003, ch. 4).

${ }^{41}$ We use the simple first order Euler scheme here in order to avoid too much technicality in our presentation. For higher order discrete time approximations see, e.g., Chapter 5 of Grüne (2002).

${ }^{42}$ Of course, this discussion concerns the spatial discretization error only. For the analysis of the full error we refer to the cited references. 


\section{Figures}

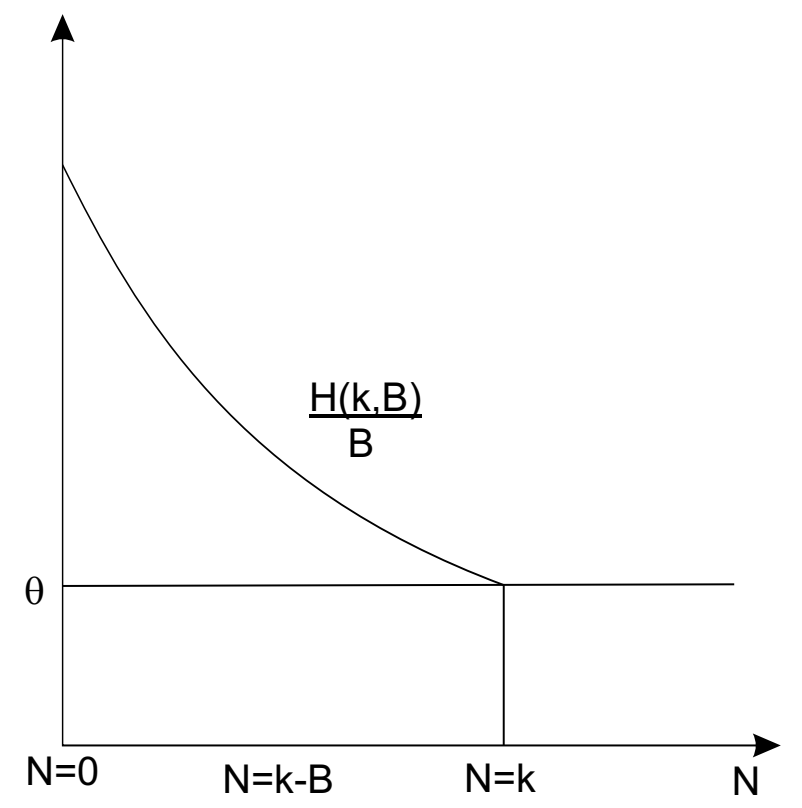

Figure 1: Endogenous Credit Cost 


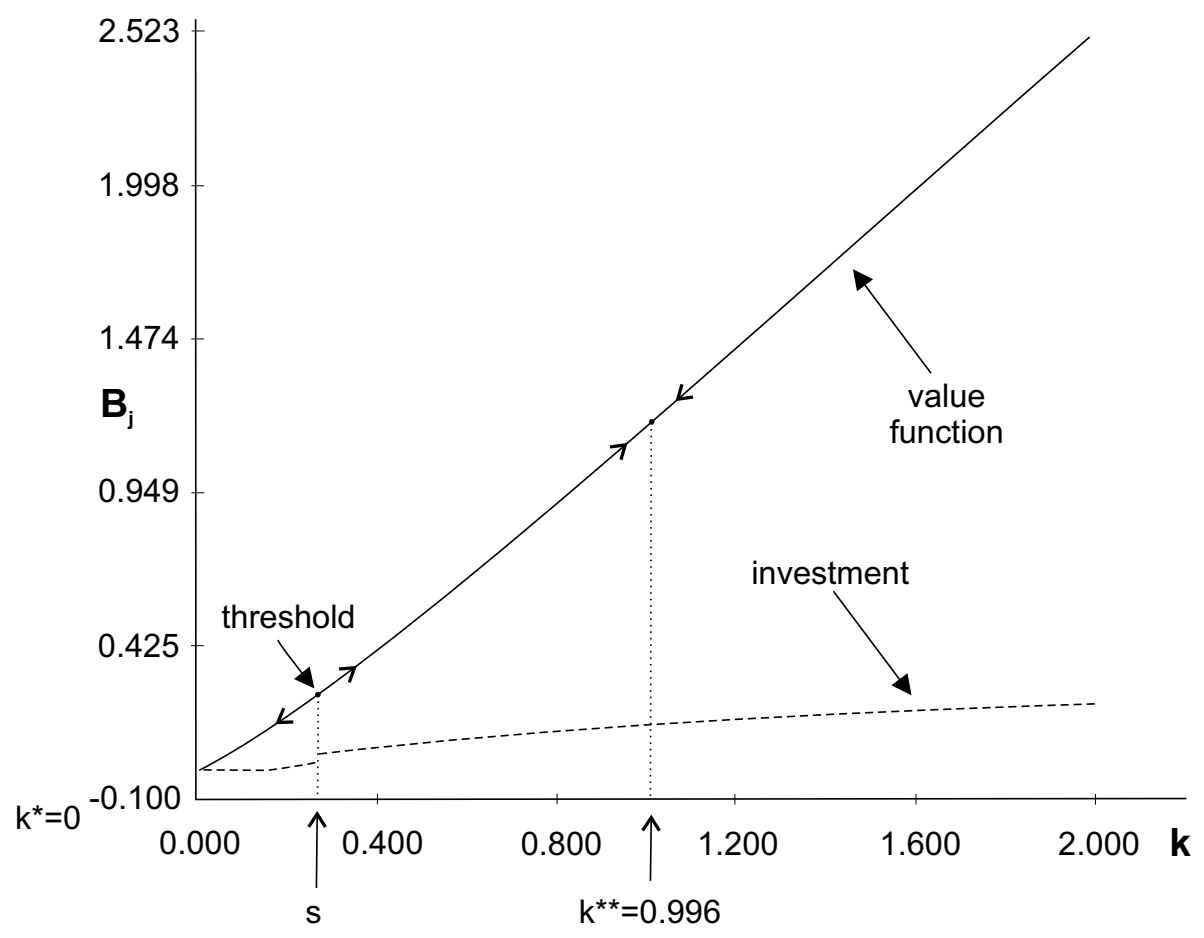

Figure 2: Optimal value function and optimal investment 


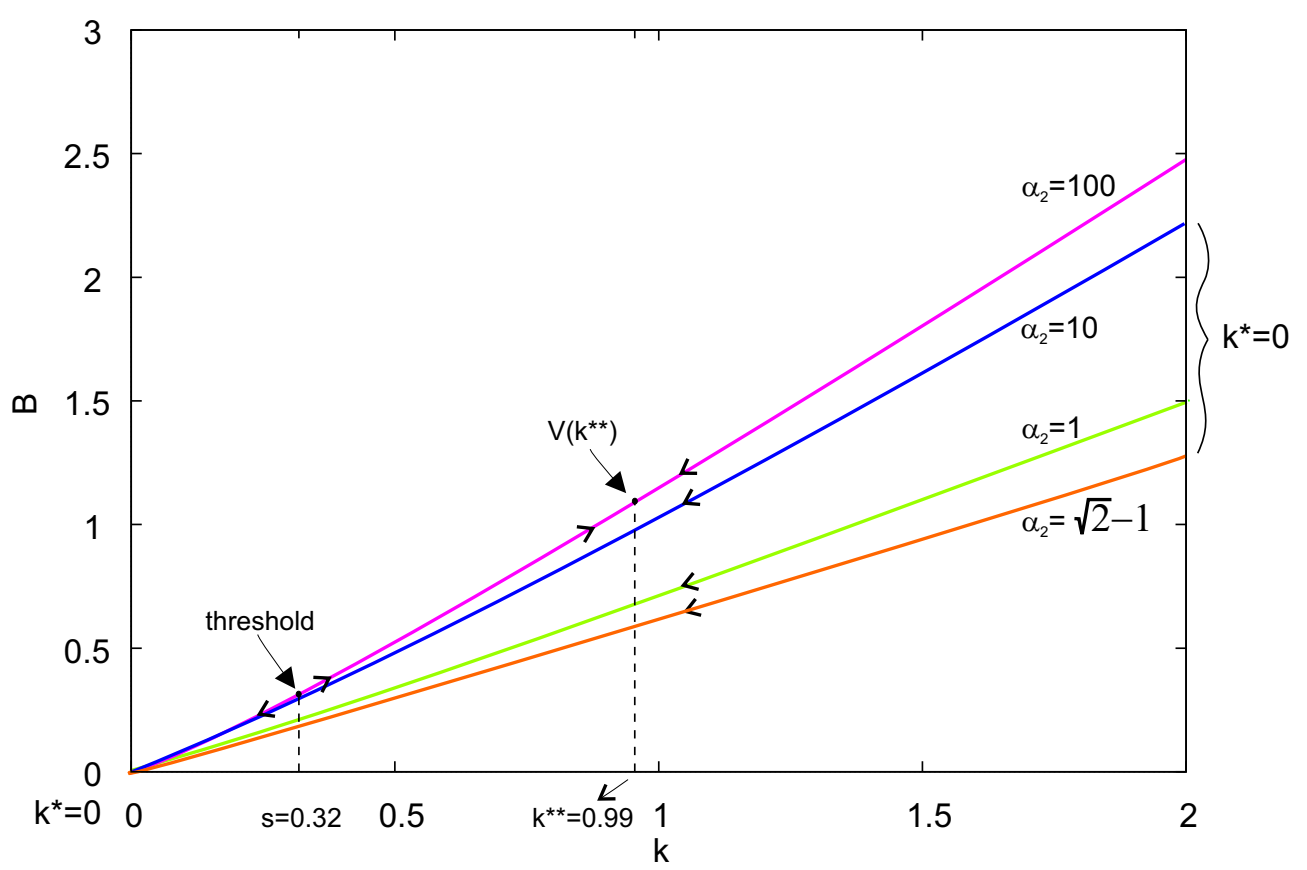

Figure 3: Present value curve $V(k)$ for different $\alpha_{2}$ 

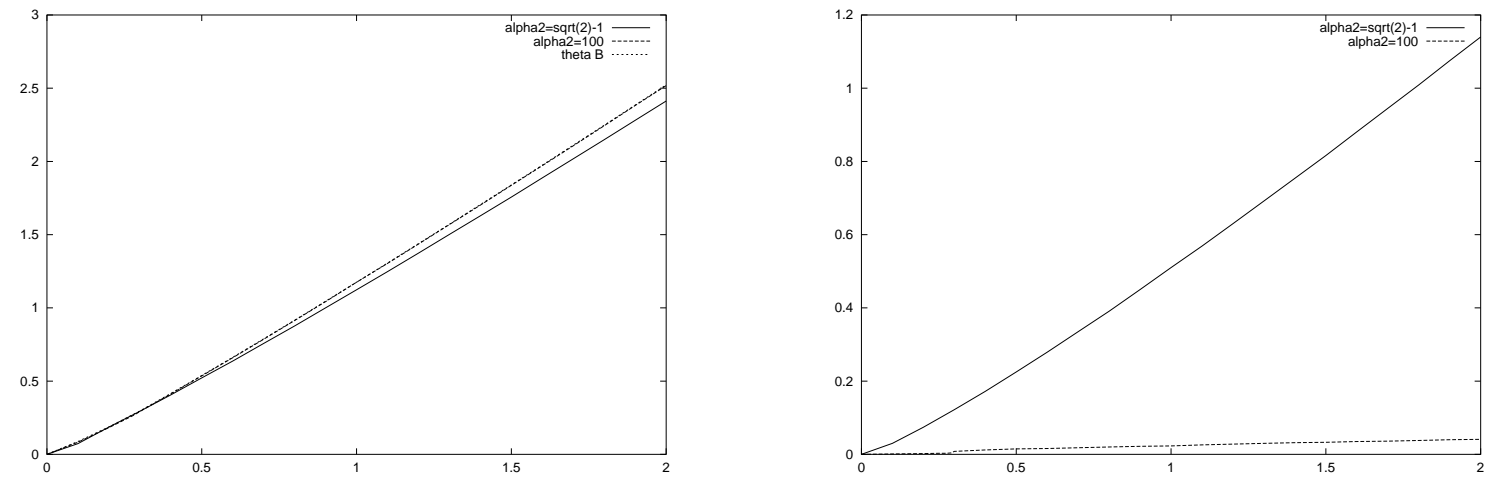

Figure 4: Value $V(k)$ (left) and Value loss $V_{H}(k)$ (right) for Different Endogenous Credit Cost 

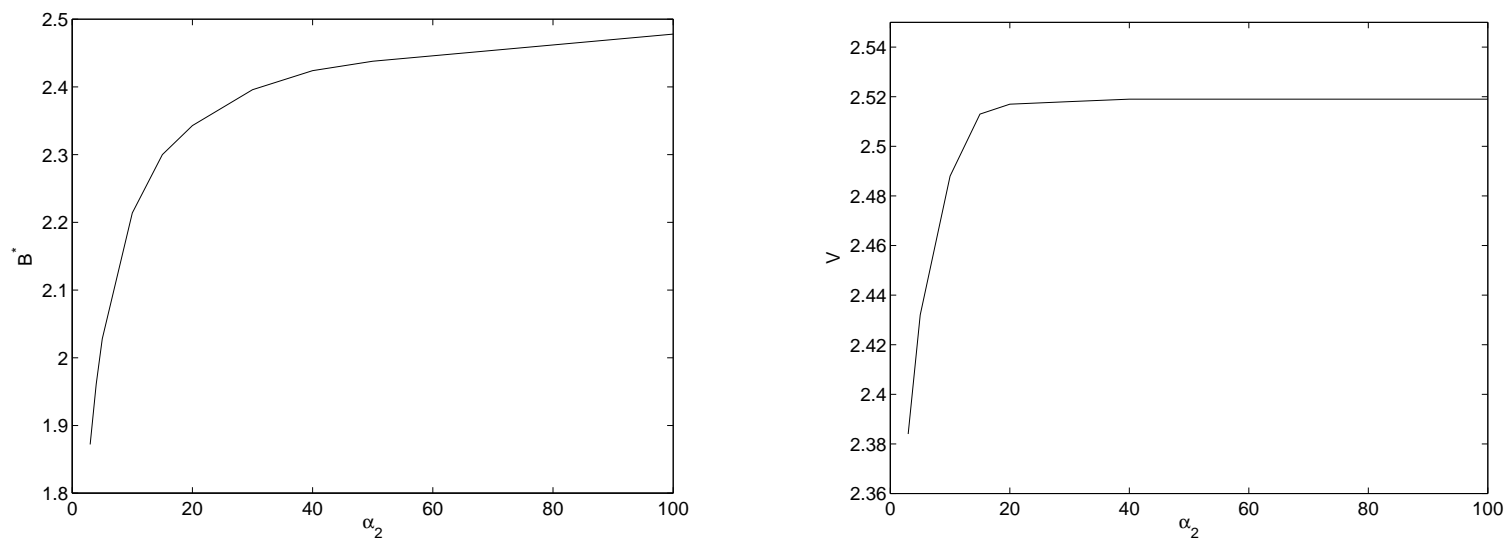

Figure 5: $B^{*}(k)$ (left) and $V(k)$ (right) at $k=2$ for varying $\alpha_{2}$ 


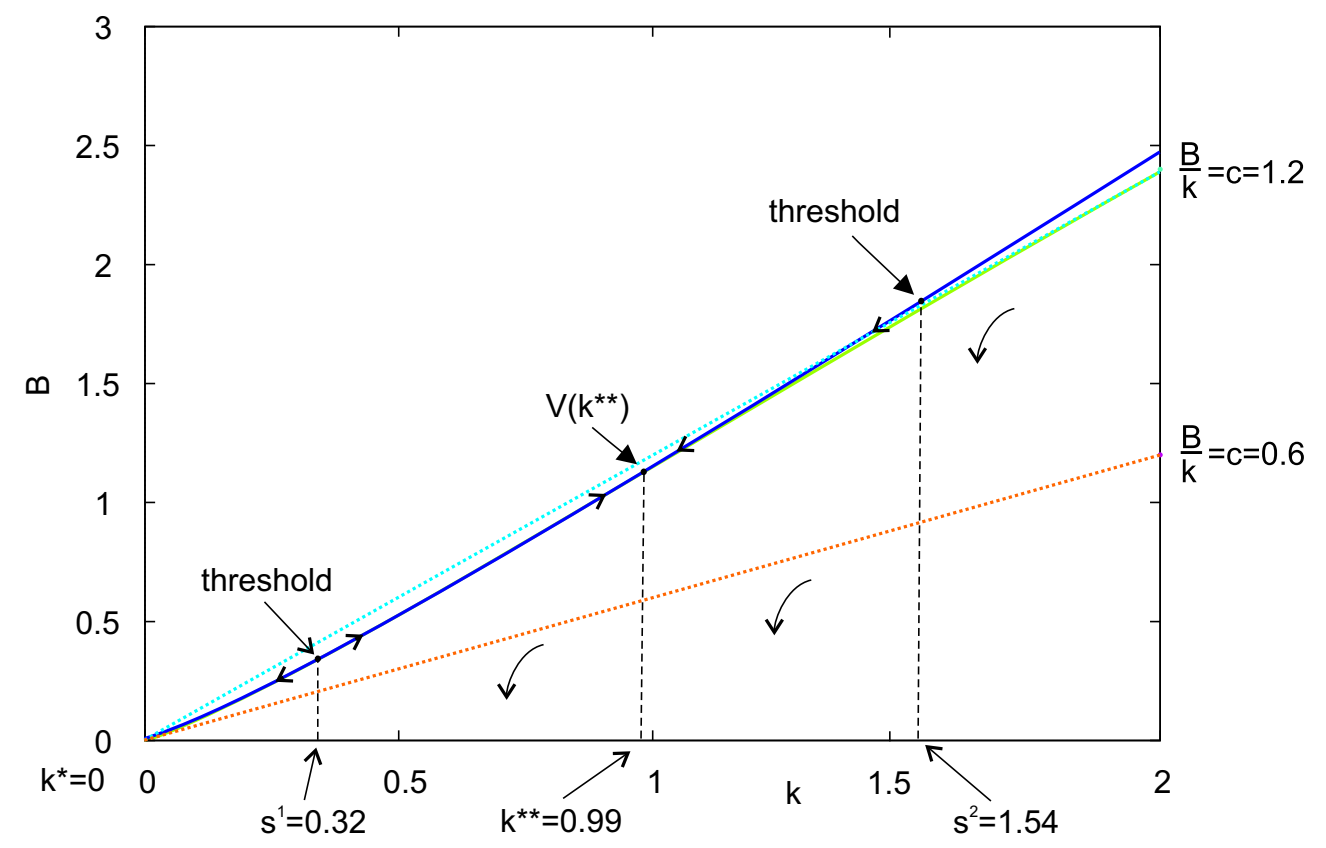

Figure 6: Present value curve $V(k)$ for different debt ceilings, $H(k, B)$ from ( 1) 


\section{References}

[1] Abel and Blanchard (1986), "The Present Value of Profits and Cyclical Movements in Investment", Econometrica 54(2): 246-273.

[2] Abel and J.C. Eberly (1994), "United Model of Investment under Uncertainty", American Economic Review, 84(5): 1369-1384.

[3] Bardi, M. and Capuzzo Dolcetta, I. (1997), "Optimal control and viscosity solutions of Hamilton-Jacobi-Bellman equations", Boston, MA: Birkhäuser.

[4] Benninga, S. (2000), Finanancial Modeling, Cambridge, MIT-Press.

[5] Bernanke, B., Gertler, M. and S. Gilchrist (1999), "The Financial Accelerator in a Quantitative Business Cycle Framework", in J. Taylor and M. Woodford (eds), Handbook of Macroeconomics, Amsterdam, NorthHolland.

[6] Beyn, W.-J., T. Pampel and W. Semmler (2001), "Dynamic Optimization and Skiba Sets in Economic Examples", Journal of Optimal Control Applications and Methods, 22: 251-280.

[7] Capuzzo Dolcetta, I. (1983), On a Discrete Approximation of the Hamilton-Jacobi Equation of Dynamic Programming, Appl. Math. Optim., vol. 10, pp. 367-377.

[8] Carlstrom, C.T. and T.S. Fuerst (1997), Agency Cost, Net Worth and Business Fluctuations: A Compatible General Equilibrium Analysis, The American Economic Review, December, pp: 893-910

[9] Cochrane, J. (1991), "Production-Based Asset Pricing and the Link Between Stock Returns and Economic Fluctuations", Journal of Finance, 46(1), pp. 209-237.

[10] Cochrane, J. (1996), "A Cross-Sectional Test of an Investment-Based Asset Pricing Model", Journal of Political Economy, 104(3), pp. 572621.

[11] Cochrane, J. (2000), "Asset Pricing", Princeton: Princeton University Press.

[12] Cooley, T. and V. Quadrini (1998) "Monetary Policy and the Financial Decisions of Firms", University of Rochester, mimeo 
[13] Duan, J.C., G. Gauthier, J. Simonato and S. Zaanoun (2002), Estimating Merton's Model by Maximum Likelihood with Survivorship Consideration, working paper, Rotman School of Management, University of Toronto.

[14] Falcone, M. (1987), A Numerical Approach to the Infinite Horizon Problem of Deterministic Control Theory, Appl. Math. Optim., vol. 15, pp. 113. Corrigenda (1991), ibid., vol. 23, 213-214.

[15] Flaschel, P., R. Franke and W.Semmler (1997), Dynamic Macroeconomics, Cambridge, MIT-Press.

[16] Gertler, M. and S. Gilchrist (1994), "Monetary Policy, Business Cycles and the Behavior of Small Scale Firms", Quarterly Journal of Economics, vol. CIX, May.

[17] Gomes, J.F., A. Yaron and L. Zhang (2002), "Asset Pricing Implications of Firms' Financing Constraints", working paper, The Wharton School, University of Pennsylvania.

[18] Grüne, L. (1997), "An Adaptive Grid Scheme for the Discrete HamiltonJacobi-Bellman Equation", Numerische Mathematik vol. 75, pp. 9-337.

[19] Grüne, L, M. Metscher and M. Ohlberger (1999), On Numerical Algorithm and Interactive Visualization for Optimal Control Problems, Comput. Vis. Sci., vol. 1, pp. 221-229.

[20] Grüne, L. (2001), Subdivision Techniques for the Computation of Domains of Attraction and Reachable Sets, Proc. of NOLCOS 2001, St. Petersburg, Russia, pp. 762-767.

[21] Grüne, L. (2002), Asymptotic Behavior of Dynamical and Control Systems under Perturbation and Discretization, Lecture Notes in Mathematics, Springer Verlag, to appear.

[22] Grüne, L., W. Semmler and M. Sieveking (2003), "Creditworthiness and Thresholds in a Credit Market Model with Multiple Equilibria", forthcoming Economic Theory, vol 25, no 2: 287-315, 2004/5.

[23] Grüne, L. and W. Semmler (2002), "Using Dynamic Programming with Adaptive Grid Scheme for Optimal Control Problems in Economics", forthcoming Journal of Economic Dynamics and Control, vol 28: 2427$2456,2004 / 5$. 
[24] Grüne, L. and W. Semmler (2003), "Solving Asset Pricing Models with Stochastic Dynamic Programming", paper prepared for the conference of the Society of Comutational Economics, Seattle, July 2003, CEM working paper, Bielefeld University.

[25] Hankel, M. (2003), "Credit Risk, Capital Structure and the Pricing of Equity Options", Heidelberg and New York, Springer Publishing House.

[26] Judd, K. and B. Petersen (1986): "Dynamic Limit Pricing and Internal Finance", Journal of Economic Theory 39, pp. 368-399.

[27] Kiyotaki, N. and J. Moore (1997) Credit Cycles, Journal of Political Economy, vol 105, April:211-248.

[28] Krieger, S. (1999), "Bankruptcy Costs, Financial Constraints and the Business Cycle", Yale University, mimeo

[29] Lettau, M. and Ludvigson (2002), "Time Varying Risk Premia and the Cost of Capital: An Alternative Implication of the Q Theory of Investment", Journal of Monetary Economics, 49: 31-66.

[30] Merton, R.C. (1974): "On the Pricing of Corporate Debt: The Risk Structure of Interest Rates", Journal of Finance, 2: 449-470.

[31] Miller, M. and J. Stiglitz (1999), Bankruptcy Protection against Macroeconomic Shocks, mimeo, The World Bank.

[32] Rouwenhorst, G.K. (1995), Asset Pricing Implications of Equilibrium Business Cycle Models, in: T. Cooley "Frontiers of Business Cycle Research", Princeton, Princeton University Press.

[33] Semmler, W. (2003), "Asset Prices, Booms and Recessions", Heidelberg/New York, Springer Publishing House.

[34] Semmler, W. and M. Sieveking (1996), "Computing Creditworthiness and Sustainable Debt", Dept. of Mathematics, University of Frankfurt, paper presented at the Conference on "Computing in Economics and Finance", University of Geneva, June, 1996.

[35] Semmler, W. and M. Sieveking (1999), Using Vector Field Analysis for Studying Debt Dynamics, paper presented at the North American Winter Meeting of the Econometric Society, Chicago, 1998, mimeo, University of Bielefeld. 
[36] Semmler, W. and M. Sieveking (2000), Critical Debt and Debt Dynamics, Journal of Economic Dynamics and Control, vol 24:1121-44.

[37] Sieveking, M. and W. Semmler (1999), Credibility, Dept. of Economics, University of Bielefeld, mimeo

[38] Sieveking, M, and W. Semmler (1998), The Optimal Value of Consumption, Dept. of Economics, University of Bielefeld, mimeo.

[39] Sieveking, M. and W. Semmler (1997), "The Present Value of Resources with Large Discount Rates", Applied Mathematics and Optimization: An International Journal, 35:283-309.

[40] Tobin, J. (1969), A General Equilibirum Approach to Monetary Theory, Journal of Money, Credit and Banking 1, (1) 15-29.

[41] Townsend, R. (1979), "Optimal Contracts and Competitive Markets with Costly State Verification", Journal of Economic Theory, 21: 265293. 